\title{
Organization and Expression of a Multigene Family Encoding the Surface Glycoproteins of Trypanosoma cruzi Metacyclic Trypomastigotes Involved in the Cell Invasion
}

\author{
Mirian S Carmo, Jorge E Araya*, Marcel I Ramirez, Silvia Boscardin, \\ Maria I Cano/ ${ }^{++}$, Renata P Baida, Rita C Ruiz, Marcia R Santos, Miguel A \\ Chiurillo**, José L Ramirez**, Nobuko Yoshida, José Franco da Silveira/ ${ }^{+}$
}

Departamento de Micro, Imuno e Parasitologia, Escola Paulista de Medicina, Unifesp, Rua Botucatu 862, 04023062 São Paulo, SP, Brasil *Unidad de Parasitologia, Universidad de Antofagasta, Av. Coloso s/n, Casilla 170, Antofagasta, Chile **Instituto de Biologia Experimental, Universidad Central de Venezuela, Aptado 47525, Caracas 1041-A, Venezuela

Key words: Trypanosoma cruzi - metacyclic trypomastigotes - surface glycoprotein genes - genomic organization - transcription

The infective forms of Trypanosoma cruzi are the trypomastigote stages found in the bloodstream of mammalian hosts or the metacyclic trypomastigotes present in the digestive tract of the insect. Metacyclic trypomastigotes express two stage-specific glycoproteins (gp90 and gp82) that have no counterpart in blood trypomastigotes (Yoshida 1983, Teixeira \& Yoshida 1986). The gp90 and gp82 are involved in the penetration of the parasite into host cells (Araguth et al. 1988, Yoshida et al. 1993, Ramirez et al. 1993, Santori et al. 1996a). Gp82 can induce $\mathrm{Ca}^{2+}$ signal in target cells (Dorta et al. 1995, Ruiz et al. 1998), an event essential for $T$. cruzi internalization (Dorta et al. 1995). Gp90 and gp82 are also relevant immunologically. Immunization with gp90 or gp82 protects mice against acute infection by $T$. cruzi (Araguth et al. 1988, Gonzalez et al. 1991, Yoshida et al. 1993, Santori et al. 1996b). Here we present studies on the genomic organization and expression of genes encoding gp90 and gp82.

\section{STRUCTURE OF $g p 90$ AND $g p 82$ GENES}

cDNA clones encoding gp 82 and gp90 were isolated from expression libraries using specific monoclonal antibodies (Franco et al. 1993, Araya

This work was supported by grants from Fapesp, Pronex, UNDP/World Bank/WHO/TDR, Cyted (Ibero American Project of Biotechnology, SubProgram III, Spain). +Corresponding author: Fax: +55-11-571.10 95. E-mail: franco.dmip@epm.br.

${ }^{++}$Present address: Department of Microbiology, University of San Francisco, San Francisco, CA, USA.

Received 9 June 1999

Accepted 9 August 1999 et al. 1994). Analysis of cDNA clones encoding gp82 and gp90 revealed the existence of several post-translational modifications such as $\mathrm{N}$ glycosylation and addition of a GPI anchor (Franco et al. 1993, Araya et al. 1994). The open reading frames (ORF) of gp82 cDNA clones encode polypeptides of 516 to 595 amino acids with molecular masses of 55.6 to $64 \mathrm{kDa}$, which are lower than the 70-kDa polypeptide devoid of $N$-linked oligosaccharides, which is the precursor to the gp82. Structurally, gp82 and gp90 are surface glycoproteins containing $N$-linked oligosaccharide side chains and anchored to the membrane through a glycosylphosphatidylinositol (GPI) moiety (Schenkman et al. 1989, Yoshida et al. 1990, Ramirez et al. 1993, Cardoso de Almeida \& N Heise 1993, Araya et al. 1994, Ramirez et al. 1998).

Heterologous expression of gp82 in mammalian cells indicates that the requirements for translocation of the nascent polypeptide across the endoplasmic reticulum and membrane glycosylphosphatidyl-inositol anchoring are distinct in mammals and T. cruzi (Ramirez et al. 1998, 1999). In the carboxy-terminal domain of gp82 and gp90 was identified a cleavage/attachment site for GPI anchor addition ( $\omega$ site) composed by the following residues: aspartic, glycine and serine (Ramirez et al. 1999). The $\omega$ site $(\omega=$ Asp, $\omega+1=$ Glyc, $\omega+2=$ Ser) of gp82 and gp90 differs from that found in GPI linked proteins of mammalian cells in which serine is at site $\mathrm{w}$ and alanine or glycine are found at site $\omega+2$ (Udenfriend \& Kodukula 1995). The presence of aspartic acid and serine at sites $\omega$ and $\omega+2$ in the gp90 and gp82 suggests that transamidase of these organisms are different from that of mammalian cells. We could speculate that the binding pocket of mammalian transamidase is not large 
enough to accomodate two slightly larger residues as aspartic acid and serine at sites $\omega$ and $\omega+2$ present in trypanosome GPI signal. The differences found between trypanosomes and mammalian host cells could be useful for the development of specific antiparasite drugs.

Comparison of sequences of gp 90 and gp82 showed $40 \%$ identity at amino acid level, with homologous regions separated by sequences displaying significant amino acid differences (Franco et al. 1993, Araya et al. 1994). Sequence analysis of gp90 and gp 82 also revealed 40-60\% identity at amino acid level with members of T. cruzi gp85/ sialidase family (Cross \& Takle 1993, Colli 1993). Camptella et al. (1992) suggested that the T. cruzi surface antigens may have originated from an ascentral (neuraminidase) gene, and proposed the grouping of these gene families in a superfamily of $T$. cruzi surface antigens. Based on these structural features, $g p 90$ and $g p 82$ genes could be considered as members of gp85/sialidase family. The gene family encoding metacyclic surface antigens could be included in the group II of the gp85/ sialidase family together with the glycoproteins of $85 \mathrm{kDa}$ (gp85, Tc85, TSA-1, Tt34c1, SA85) expressed in bloodstream trypomastigotes.

\section{GENOMIC ORGANIZATION OF gp90 AND gp82 GENES}

The genes $g p 90$ and gp90 are organized in subsets spread out in the genome. To study the organization of these genes several distinct YACs were isolated from a library constructed with DNA from the T. cruzi clone CL Brener (Ferrari et al. 1997). The $T$. cruzi YAC library containing about 3,000 recombinant clones with a mean insert size of 365 $\mathrm{kb}$ and representing more than 10 genome equivalents, was screened by hybridization and PCR with a sequence that encodes the $\mathrm{C}$-terminal domain of gp90. Twenty four YACs (mean insert size $=150$ to $450 \mathrm{~kb}$ ) were isolated and characterized. Restriction mapping and hybridization analysis showed that several YACs may contain at least two copies of gene gp90. A common feature of the YACs was the presence of other members of gp85/sialidase family such as $g p 85$ and $g p 90$ indicating that genes gp90 and genes $g p 82$ and/or $g p 85$ are linked at multiple sites of the genome.

Gp90 and gp82 are present in multiple copies, distributed in several chromosomes, and this gene family can be divided into subsets on the basis of hybridization patterns obtained with probes derived from different regions of gp90 and gp82 genes (Araya et al. 1994, Cano et al. 1995, Santos et al. 1997). Many members of gp90 and gp82 gene family are closely linked to members of gp $85 /$ sialidase family at multiple sites in the genome of different T. cruzi strains. Hybridization patterns of $g p 90$, gp82 and gp85 genes with $T$. cruzi chromosomal bands separated by pulsed field gel electrophoresis are very similar, suggesting that many of these genes could be linked in different chromosomal loci. This was confirmed by isolation of genomic DNA clones from YAC and cosmid libraries as described above.

It is interesting to note that some several subtelomeric regions are made of sequences associated to the gp90 and gp85 (Chiurillo et al. 1999). The presence of gp90 and gp85 at T. cruzi telomeres suggests that new variants of the gp85/sialidase family can continously be arising by duplication, mutation, and recombination of copies that have been transposed to the telomeres.

\section{TRANSCRIPTION OF $g p 90$ AND $g p 82$ GENES}

Northern blot and western blot analyses showed that gp90 and gp82 are preferentially transcribed and expressed in the metacyclic trypomastigote stage (Franco et al. 1993, Araya et al. 1994). Further studies on the transcription of these genes using "run on" and RNA-PCR assays showed the presence of gp82 and gp90 transcripts in epimastigotes and blood trypomastigotes. Taken together these results suggest that the expression of genes gp 90 and gp 82 is constitutive and may be regulated at post-transcriptional level, for instance, at translational level and/or mRNA stabilization.

\section{IDENTIFICATION OF $g p 82$ AND $g p 90$ HOMOLOGUES IN TRYPANOSOMA RANGELI}

The non pathogenic protozoon $T$. rangeli and T. cruzi share several characteristics, including the minicircle structure and several antigenic determinants, suggesting that both parasites are closely related. A comparative analysis of the T. cruzi gp82/ gp90 and $T$. rangeli related sequences may aid in the determination of the features of gp 82 and gp 90 proteins that contribute to its function in host cell interactions.

The presence of multiple copies of genes in $T$. rangeli enconding products related to $T$. cruzi gp82, gp90 and gp85 was revealed when genomic $T$. rangeli DNA was hybridized at moderate and high stringencies with $g p 82, g p 90$ and $g p 85$ genes. Even at high stringency conditions, both probes hybridized with several genomic fragments suggesting that gp82, gp90 and gp85 related sequences are interspersed in the genome rather than arranged in tandem repeats. Sequence analysis showed that many of hybridizing fragments contain sequences associated to the gp85/sialidase gene family. These results suggested that gp90, gp82 and gp85 genes have been originated from a common ancestral gene present in several member of Trypanosoma genus. 


\section{REFERENCES}

Araguth MF, Rodrigues MR, Yoshida N 1988. Trypanosoma cruzi metacyclic trypomastigotes: neutralization by the stage-specific monoclonal antibody $1 \mathrm{G} 7$ and immunogenicity of 90-kilodalton surface antigen. Parasite Immunol 10: 707-710.

Araya JE, Cano MI, Yoshida N, Franco da Silveira J 1994. Cloning and characterization of a gene for the stage-specific gp $82 \mathrm{kDa}$ surface antigen of metacyclic trypomastigotes of Trypanosoma cruzi. Mol Biochem Parasitol 65: 161-169.

Campetella O, Sanchez D, Cazzulo JJ, Frasch ACC 1992. A superfamily of Trypanosoma cruzi surface antigens. Parasitol Today 8: 378-381.

Cano MI, Gruber A, Vasquez M, Cortes A, Levin MJ, Gonzalez A, Degrave WM, Rondinelli E, Zingales B, Ramirez JL, Alonso C, Requema JM, Franco da Silveira J 1995. Molecular karyotype of clone CL Brener chosen for the Trypanosoma cruzi genome project. Mol Biochem Parasitol 71: 273-278.

Cardoso de Almeida ML, Heise N 1993. Proteins anchored via glycosylphosphatidylinositol and solubilizing phospholipases in Trypanosoma cruzi. Biol Res 26: 285-312.

Chiurillo M, Cano MI, Franco da Silveira J, Ramirez JL 1999. Structure and organization of telomeric and subtelomeric regions of chromosomes from the protozoan parasite Trypanosoma cruzi. Mol Bioch Parasitol (in press).

Colli W 1993. Trans-sialidase: a unique enzyme activity discovered in the protozoon Trypanosoma cruzi. FASEB J 7: 1257-1264.

Cross GAM, Takle GB 1993. The surface trans-sialidase family of Trypanosoma cruzi. Ann Rev Microbiol 47: 385-411.

Dorta ML, Ferreira A, Oshiro MEM, Yoshida N 1995. $\mathrm{Ca}^{2+}$ signal induced by Trypanosoma cruzi metacyclic trypomastigote surface molecules implicated in mammalian cell invasion. Mol Biochem Parasitol 73: 285-89.

Ferrari I, Brandariz, S, Santos MR, Lorenzi H, Requena JM, Schijman A, Vazquez M, Franco da Silveira J, Ben Dov C, Medrano C, Kaplan D, Ghio S, Elias F, López Bergami P, Cano MI, Zingales B, Urmenyil T, Rondinelli E, Gonzalez A, Cortes A, Alonso C, Ramirez JL, Chiurrillo MA, Rangel Aldao R, Brandão A, Degrave W, Perrot V, Saumier M, Billaut A, Cohen D, LePaslier D, Levin MJ 1997. Towards the physical map of Trypanosoma cruzi nuclear genome: constrcution of YAC and BAC libraries of the reference clone $T$. cruzi CL Brener. Mem Inst Oswaldo Cruz 92: 843-858.

Franco FRS, Paranhos-Baccala G, Yamauchi LM, Yoshida N, Franco da Silveira J 1993. Characterization of a cDNA clone encoding the carboxy-terminal domain of 90-kDa surface antigen of Trypanosoma cruzi metacyclic trypomastigotes. Infect Immun 61: 4196-4201.

Gonzalez J, Araguth MF, Yoshida N 1991. Resistance to acute Trypanosoma cruzi infection resulting from immunization of mice with $90-\mathrm{kDa}$ antigen from metacyclic trypomastigotes. Infect Immun 59: 863-867.
Ramirez MI, Ruiz RC, Araya JE, Franco da Silveira J, Yoshida N 1993. Involvement of the stage-specific 82-kilodalton adhesion molecule of Trypanosoma cruzi metacyclic trypomastigotes in host cell invasion. Infect Immun 6: 3636-3641.

Ramirez MI, Boscardin SB, Ruiz RC, Han SW, ParanhosBaccala G, Yoshida N, Mortara RA, Franco da Silveira J 1998. Expression, processing and cellular traffiching of a Trypanosoma cruzi Surface Glycoprotein (gp82) in mammalian background. Mem Inst Oswaldo Cruz 93 (Suppl. II): 53-54.

Ramirez MI, Boscardin SB, Ruiz RC, Han SW, ParanhosBaccala G, Yoshida N, Mortara RA, Franco da Silveira J 1999. Heterologous expression of a Trypanosoma cruzi surface glycoprotein (gp82) indicates that requirements for glycosylphosphatidylinositol (GPI) anchoring are different in mammalian cells and this trypanosome. Mem Inst Oswaldo Cruz (in press).

Ruiz RC, Favoreto S, Dorta ML, Oshiro MEM, Ferreira AT, Manque PM, Yoshida N 1998. Infectivity of Trypanosoma cruzi stains is associated with differential expression of surface glycoproteins with differential $\mathrm{Ca}^{2+}$ signaling activity. Biochem J 330: 505511.

Santori FR, Dorta ML, Juliano L, Juliano MA, Franco da Silveira J, Ruiz RC, Yoshida N 1996a. Identification of a domain of Trypanosoma cruzi metacyclic trypomastigote surface molecule gp 82 required for attachment and invasion of mammalian cells. $\mathrm{Mol}$ Biochem Parasitol 78: 209-216.

Santori FR, Paranhos-Baccala G, Franco da Silveira J, Yamauchi LM, Araya JE, Yoshida N 1996b. A recombinant protein based on Trypanosoma cruzi metacyclic trypomastigote $82 \mathrm{kDa}$ antigen that induces an effective immune response to acute infection. Infect Immun 64:1093-1099.

Santos MRS, Cano MI, Schijman A, Vazquez M, Levin MJ, Ramirez JL, Brandão A, Degrave WM, Franco da Silveira J 1997. Trypanosoma cruzi genome project: nuclear karyotype and gene mapping of clone CL Brener. Mem Inst Oswaldo Cruz 92: 821828.

Schenkman S, Yoshida N, Cardoso de Almeida ML 1989. Glycosylposphatidylinositol-anchored proteins in metacyclic trypomastigotes of Trypanosoma cruzi. Mol Biochem Parasitol 29: 141-152.

Teixeira MMG, Yoshida N 1986. Stage-specific surface antigens of metacyclic trypomastigotes of Trypanosoma cruzi identified by monoclonal antibody. Mol Biochem Parasitol 18: 271-282.

Udenfriend S, Kodukula K 1995. How glycosylphophatidylinositol anchored membrane proteins are made. Ann Rev Microbiol 64: 563-591.

Yoshida N 1983. Surface antigens of metacyclic trypomastigotes of Trypanosoma cruzi. Infect Immun 40: 836-839.

Yoshida N, Araya JE, Franco da Silveira J, Giorgio S 1993. Antibody production and T cell response induced by stage-specific surface glycoproteins purified from metacyclic trypomastigotes. Exp Parasitol 77: 405-413. 